\title{
Construction of Evaluation Index System of Marketing Competitiveness
}

\author{
Jing Qin \\ Zhongshan Polytechnic, Zhongshan, Guangdong, 528403
}

Keywords: evaluation index system; marketing competitiveness; construction

\begin{abstract}
With the development of economy, if companies want to gain a firm foothold in the fierce market competition, they must enhance their own marketing competitiveness, strengthen their own market value, and at the same time increase their overall strength, fit with the actual business situation. The situation evaluation index system has caused widespread concern among economists. This paper starts with the case analysis, analyzes the construction basis of the evaluation index system of marketing competitiveness, and emphatically explains the construction steps of the evaluation index of marketing competitiveness, aiming to provide valuable reference for evaluation indicators.
\end{abstract}

\section{Introduction}

Marketing competitiveness refers to the ability of an enterprise to gain comparative advantages in market competition through systematic marketing efforts, create customer value, achieve mutual benefit exchanges, and achieve the goals of the company and related stakeholders according to the marketing environment and its own resource conditions. Marketing competitiveness occupies a very important position in the theory of enterprise competitiveness. More and more evidence and research show that the core competitiveness is the foundation for the long-term survival and development of the company, and the marketing competitiveness is the most important component of the company's core competitiveness [1]. For the study of the competitiveness of corporate marketing, although the academic community has published a lot of literature, it has not yet seen a relatively complete and operational evaluation index system. Therefore, establishing an enterprise marketing competitiveness evaluation index system is a pioneering system project. Based on the existing marketing theory and corporate marketing practice, this article attempts to put forward a preliminary idea about establishing an enterprise marketing competitiveness evaluation index system, in order to seek to attract attention.

\section{Principles in Establishing an Evaluation Index System for Enterprise Marketing Competitiveness}

In accordance with the principles and requirements of unification of empirical and normative research in scientific research, there are two general guiding principles for establishing an enterprise marketing competitiveness evaluation index system. One is scientific and the other is practical. In order to meet the requirements of these two guiding principles, the following specific principles should be followed in establishing the evaluation index system for corporate marketing competitiveness: Since the 1980s, marketing theory has been inherited from modern marketing to manage Based on the rational core of guidance, new marketing experiences and lessons have been continuously summed up, and many new theoretical ideas have been developed. Among them, the core marketing theories are mainly: customer value and customer satisfaction theory, positioning theory, relationship marketing theory, integrated marketing communication theory. These theories have an essential decisive and guiding significance for the basic structure, logical consistency and content integrity of the evaluation index system of marketing competitiveness. The theory of customer value and customer satisfaction and relationship marketing theory not only reflect the values of corporate marketing, but also reveal the true meaning of marketing competition. The marketing competition among enterprises is actually the competition of customer exiled value 
provided by different companies. By increasing the total customer value (consisting of product value, staff value, image value, and service value), lowering the total customer cost (consisting of monetary cost, time cost, mental cost, and physical cost), achieving customers matching the company's profit target The maximization of the value of transfer is the fundamental way to increase the competitiveness of the enterprise's marketing. Customer satisfaction theory and relational marketing theory are all marketing theories aiming at retaining old customers, fostering customer loyalty, and realizing the long-term development of the company. Based on the research on the formation mechanism of customer satisfaction psychology, customer satisfaction theory proposes a multi-level, multi-faceted approach to customer satisfaction. From the perspective of system theory, value theory, and process theory, relationship marketing theory puts forward the principles and methods for companies to deal well with the relationships between many stakeholders in marketing [2]. The positioning theory and the integrated marketing communication theory are the most direct and indiscriminate ways to obtain the competitive advantage of marketing. Positioning theory elaborates that in the marketing environment where advertisements are flooded, information explosions, consumers' intelligence capacity is limited to information, and market competition is becoming increasingly fierce, products, brands, and companies are ingeniously designed and given certain characteristics. To establish a certain image so that they occupy the unique and valuable status of the customer's mind. Positioning science or not, is directly related to whether the company can successfully achieve "the thrilling jump of commodities to money." The theory of integrated marketing communication is an important theoretical pillar of the evaluation index system for corporate marketing competitiveness, mainly because it is such a theory: it advocates that enterprises understand the consumer's information needs through a reasonable marketing organization structure, and establish consumers. Based on this information database, and based on the unified information and core ideas of marketing communications, it uses a variety of forms of communication to conduct long-term two-way communication with consumers in order to achieve the best communication effect, namely, promote sales, create and enhance brand value, Establish and consolidate long-term good relationships between businesses and consumers. The above theories center around the core of marketing management-exchange, essence-demand management, and ultimate goal - the long-term survival and development of the enterprise. The principles and methods for improving the competitiveness of the enterprise's marketing are elaborated from different perspectives. They infiltrate each other, complement each other, complement each other, and together constitute the theoretical basis for the evaluation index system of corporate marketing competitiveness.

\section{Basic Structure Product of Enterprise Marketing Competitiveness Evaluation Index System}

Quality management capabilities. The first refers to the product-oriented quality that meets the technical requirements and standards and can reach the specified standards. The dimension of engineering-oriented quality is a single nature, and the constant of the standards that the product is centered on. The second is market-oriented quality. Market-oriented quality involves multiple levels, not only that quality is a product or service that meets certain standards, but also that it emphasizes the fundamental value it needs to achieve to satisfy customer needs. From this perspective, the definition of marketing quality is dynamic. It cannot be simply attributed to a class of products or services that meet certain standards, but emphasizes its ability to achieve a unity of customer satisfaction and profit growth [3].

Brand management and marketing communication capabilities. The brand represents the corporate image and reputation, and a good brand identity is the foundation of the company's product reputation. The corporate value derived from the brand as the core is called brand equity. In general, the higher the brand equity, the higher the brand's popularity, credibility and customer loyalty. Brand is an important asset for enterprises to enhance their marketing competitiveness and optimize their marketing path in the increasingly homogenous market competition of product services. In particular, with the continuous development and reform of new network technologies, the gap between products and services has narrowed and the channels for marketing have become 
increasingly diversified. The homogenization and spread of information spread makes it difficult for the audience to establish a deep connection with product services. The core trend of marketing competition is to form differences with similar brands. The establishment of such deep-rooted and differentiated links needs to be established through brand building. The ultimate goal of branding is to better understand the product service and meet the different needs of consumers, that is, the formation of differentiated advantages [4]. The second is to establish a deep connection with the audience, that is, to deepen the audience for the brand. loyalty. In addition to the realization of this kind of in-depth connection through differentiated products and services, it also involves the connotation that the brand meets the expectations of the audience. Marketing communication is a necessary way to realize the brand value and enhance the marketing competitiveness of the company. Therefore, both are classified into one category.

Supply chain and sales management capabilities. The competition of modern marketing is not just a competition between a single company but a competition among multiple industries, namely the supply chain. If a company wants to obtain a differentiated marketing competitive advantage, it must achieve the perfection of the supply chain and maximize the benefits. Whether the supply chain has ultimate competitiveness depends on the difference between customer value and total customer cost. The integrated management of each element of the supply chain is to maximize the value of customer expropriation. From this perspective, the supply chain affects the market competitiveness of enterprises and is an important part of the indicator system.

\section{Corporate Marketing Competitiveness Evaluation Index System}

The specific path is to conduct statistical surveys and sample selections on the sample companies, make accurate calculations and estimates, and continuously improve the system. According to the actual situation, analyze the changes in the relationship between market conditions and competitiveness factors, and timely correct the competitiveness index evaluation system. Under the premise of practical rules, the competitiveness index evaluation system is more in line with the reality. To verify the accuracy and completeness of the system by practice, and to make appropriate amendments and additions. The rapid changes in the marketing market and the availability of critical and accurate data have important implications for the rationality and scientific nature of the index system. The specific marketing situation of the enterprise is the fundamental of the market competitiveness index system [5]. Only by starting from the actual data can we truly realize the scientific nature of the index system, can we accurately predict and evaluate the advantages and disadvantages of the market competitiveness of the enterprise. The specific path is to analyze the supply chain, communication system, and enterprise customer relationship system data through corporate marketing practices. Master the dynamic elements of corporate marketing, combine the current marketing environment and marketing model, conduct data analysis, and provide guidance based on the system. The establishment and improvement of the evaluation system must be compatible with a diversified marketing market. Once the scientific evaluation system is out of practice, it loses its guiding significance. According to the market law in practice and the change and development of the enterprise marketing model, the evaluation system is continuously improved, and the marketing development law of the company is sought on the basis of practice.

The development of marketing depends on the development of market economy and the change of audience perception. The rapid rise of new media technologies has had a transformative impact on marketing communications systems. The new technology revolution promotes the emergence of new concepts, methods, and theories in the marketing field. Based on the practice of continuously developing marketing theory, it is the theoretical basis for the evaluation index system of marketing competitiveness. What is worth exploring is that the current marketing environment facing companies is different from the past. With the changes in consumer psychology brought about by the changes in new media technologies, the consumer groups have increasingly focused on self-conscious expression and consumer experience. The traditional functional marketing theory has not fully adapted to the development of modern marketing markets. Mainly reflected in two aspects: First, the development of new media has changed the situation of the traditional media monopoly of 
the country, followed by a change in the marketing communication system. Traditional communicative marketing theory believes that one-way communication has developed to two-way communication. The integrated marketing of the brand and the establishment of the communication system have all promoted the emergence of new media marketing theory. The audience pays more attention to the interaction in the consumption process, which determines that the enterprise should use the new media to carry out the interactive communication of the audience in the process of product marketing and dissemination, and to carry out the two-way choice of consumers and the expression of self-consciousness.

\section{Conclusion}

The marketing competitiveness index evaluation system accurately predicts the overall marketing competitiveness of the company and the weak links in the marketing development process. It reduces the risk of the company's marketing, realizes the exchange of benefits, accumulates brand equity, and establishes a perfect communication channel. Directional guidance. The scientificity and accuracy of the system still need to be continuously improved in practice, but it has guiding significance for the future development of the market's marketing competitiveness and the improvement of core competitiveness.

\section{References}

[1] C.k. Prahalad, Gary Hamel. The Core Competence of Corporation [J]. HARVARD BUSINESS REVIEW, May-June, 1990.

[2] Mark R. Gallon, Harold M. Stillman and David Caotes. Putting Core Competency Thinking into Practice [J]. Research. Technology Management, May-June, 1995.

[3] Foss, N.J. and Kundsen, C. Towards the Theory of Competence of the Firm [M]. London: Routledge Corporation, 1996.

[4] Andrew Campbell \& Kathleen Sommers Luchs. Core Competence-based Strategy [M]. International Thomson Business Press, 1997.

[5] Kevin Werbach, Syndication. The Emerging Model for Business in the Internet Era [J]. HARVARD BUSINESS REVIEW, May-June, 2000. 